\title{
crédito e cartões, os ambulantes judeus no rio de janeiro
}

\author{
Fábio Sá Earp \\ Professor Adjunto do Instituto de Economia da UFRJ \\ Fania Fridman \\ Professora Adjunta do Instituto de Pesquisa e Planejamento Urbano e Regional da UFRJ
}

\section{RESUMO}

O artigo refere-se ao comércio ambulante exercido por imigrantes judeus no Rio de Janeiro na primeira metade do século XX. Tal prática, uma importante forma de inserção na economia informal urbana, apoiava-se na rede de solidariedade e nas organizações da colônia. O mascate, ao possibilitar a compra a prestação pelas camadas de baixa renda permitiu a existência de um expressivo comércio popular de bens de consumo.

Palavras-chave: klienteltshik; imigrantes; judeus; crédito; Rio de Janeiro.

\begin{abstract}
This article refers to ambulant trade performed by Jewish immigrants during the first half of the twentieth century in the city of Rio de Janeiro. That practice, an importam way of integration within the informal urban economy, was based upon the solidarity networks and organizations of the Jewish local community. The pedlar, by enabling lower income groups to buy on credit, gave origin to a sizeable popular market for consumption goods.
\end{abstract}

Key words: klienteltshik (peddlar); immigrants; jews; credit; Rio de Janeiro.

\section{Introdução}

\author{
Este artigo dedica-se a um tema ainda pouco explorado na histo- \\ riografia econômica relativo à imigração judaica para o Brasil, \\ especificamente para o Rio de Janeiro, no período que vai dofinal \\ do século XIX à primeira metade do século XX. Nossa intenção é \\ discutir uma das formas de integração social - a venda de porta em \\ porta, klienteltshik em íidiche, ofício que empregava cerca de $30 \%$ dos \\ israelitas que chegavam ao Brasil sem profissão. O primeiro ponto a
}

Uma versão preliminar deste trabalho foi apresentada nas Segundas Jornadas de História Econômica (Montevidéu,julho de 1999) e no III Congresso Brasileiro de História Econômica promovido pela ABPHE (Curitiba, setembro de 1999). 
destacar é que, se não existem textos de economistas escritos acerca do assunto, alguns deles no entanto são capazes de pesquisar criticamente a memória de suas famílias. Neste sentido adotamos alguns procedimentos típicos dos praticantes da história oral (Thompson, 1978) e organizamos entrevistas que permitiram transformar a memória em análise. ${ }^{2}$

O segundo ponto consiste na aplicação de categorias básicas das teorias de organização industrial, como custos de transação e economias de escala e de escopo, destacando os elementos que permitem a configuração do formato organizacional das firmas e de sua integração nos mercados de acordo com Chandler (1990). Assim pretendíamos elencar as principais barreiras aos imigrantes e como estes as contornaram com vistas à sua integração.

O terceiro ponto refere-se ao tratamento teórico do conjunto de relações pessoais que representou a principal vantagem comparativa dos judeus estrangeiros para sua entrada no mercado brasileiro. Aqui foi necessário desenvolver o conceito de colônia - uma rede de relações pessoais que forneceu informalmente elementos econômicos e não-econômicos que permitiram superar os obstáculos. Partindo do clássico estudo de Ben-Porath (1980) sobre firmas, famílias e amizade na formação de laços mercantis, incorporamos as noções desenvolvidas por Manuel Castells (1997) sobre a configuração de identidades sociais.

\section{A colônia como rede de solidariedade}

A forma pela qual o imigrante supera a desvantagem comparativa diante dos nacionais é sua inserção em uma rede de solidariedade, formada a partir de uma identidade comum, seja de origem religiosa (como a judaica) seja de origem nacional (polonesa) ou regional (do Oriente Médio). Uma colônia pode ainda ter subconjuntos de ordem lingüística (no caso dos judeus, os sepharadim que falam ladino e os ashkenazim que se expressam em ídiche). Em geral os laços de solidariedade e coesão são maiores quando há uma ameaça qualquer aos seus membros, como aconteceu na Europa com o anti-semitismo,

Somos especialmente gratos a Bertha Puretz Fridman (a quem dedicamos este texto in memoriam), Smil Ochs, e Sukar Caplun.Agradecemos ainda as contribuições de Carlos Lessa,José Ricardo Tauille, George Kornis, Vânia Cury e Antônio Luiz Licha. 
do que a falta de informação sobre o lugar e a língua. Neste sentido, quando a primeira geração de filhos de imigrantes, ao passar pelo processo de escolarização, obtém as mesmas informações que os nacionais, a dependência com a rede de solidariedade criada pelos seus pais pode tornar-se menos intensa. Por outro lado, a dependência mútua cria pactos de confiança entre os participantes, o que facilita as transações de todo tipo, inclusive as comerciais e financeiras. A colônia possui muitas das características de uma família, o que nos permite estabelecer comparações entre as transações interfamiliares e aquelas realizadas no seio da comunidade.

Segundo Ben-Porath (op. cit.) a relação entre os membros da família é um tipo de contrato que se caracteriza por (a) estender-se por longo e indeterminado período de tempo; (b) englobar grande quantidade de atividades; (c) não estar previa nem claramente definido, sendo contingente ou decidido como resposta a novos eventos; (d) não poder ser alterado facilmente, dada a interdependência entre os membros; (e) estabelecer relações de débito e crédito que não se expressam monetariamente pois criam dívidas simbólicas que dificilmente serão liquidadas; (f) executar as dívidas sem o recurso à justiça comum; e (g) criar uma identidade coletiva que afeta as transações de cada um dos membros com os não-membros. A mais importante característica do contrato familiar é a identidade dos participantes, não podendo ser transferível ou negociável (embora um não-membro possa ingressar no grupo por casamento).

As transações de mercado, ao contrário, envolvem preços que podem se expressar em termos de uma unidade de conta monetária e os valores envolvidos independem da identidade dos participantes - neste caso apenas as relações entre preços e quantidades importam desde que os direitos de propriedade estejam garantidos pela Lei incluindo-se aí tanto o pagamento das dívidas quanto a qualidade e a quantidade das mercadorias transacionadas. Quanto mais estes direitos de propriedades forem garantidos, menores serão os custos de transação envolvidos. Entretanto, em uma estrutura institucional deficiente em termos de garantias de direitos de propriedade os custos de transação podem ser reduzidos mediante a confiança mútua entre as partes dada pelo conhecimento da identidade dos participantes e pela certeza de que seu relacionamento será permanente. Os laços de confiança são ainda reforçados pelo tratamento privilegiado (como presentes e favores), criando dívidas simbólicas. A participação em atividades comuns, como cultos religiosos e festas 
de família, constitui um reforço adicional. A colônia funciona, assim, como uma família ampliada para o imigrante.

Quanto à construção da identidade, esta pode resultar de três processos: de legitimação, de resistência e de projeto (Castells, op. cit). A legitimação se dá através da participação do indivíduo nas instituições dominantes na sociedade (por exemplo, o sistema de ensino), o que acarreta a aceitação daquela determinada identidade. A resistência ocorre quando um grupo é estigmatizado ou perseguido, sendo obrigado a construir trincheiras culturais para sobreviver. Já o projeto surge quando a cultura é utilizada para redefinir sua identidade no bojo de uma tentativa de transformação da sociedade como um todo. Caso o intento seja bem sucedido, este passará a reproduzir a nova identidade através da legitimação. A identidade do imigrante no Brasil parece ser um caso típico de resistência diante da barreira informacional e do preconceito étnico. A coesão da comunidade será tanto maior quanto maiores forem as forças que tentam excluir seus membros, impedindo-os de desfrutar dos mesmos direitos dos demais. Esta solidariedade é particularmente forte no grupojudeu por conta do desenvolvimento, ao longo de quase dois milênios, da cultura da Diáspora na qual seus membros aprenderam a construir instituições ágeis. ${ }^{3}$

Sempre que as condições políticas permitiram, as comunidades judaicas da Diáspora estabeleceram organizações formais com finalidades religiosas, sociais, culturais e econômicas. Foram fundadas sinagogas - apesar da vinda de judeus para o Brasil ter ocorrido desde o início da colonização portuguesa, dada a perseguição religiosa há notícias de sinagogas no Rio de Janeiro datando de 1867 com a fundação da Aliança Israelita Universal e de 1873 com a União Israelita do Brasil e a Irmandade de Proteção Israelita; clubes - nas primeiras décadas do século XX existiam o Grêmio Juvenil Kadima, Clube Juventude Israelita, Clube dos Cabiras e o Centro Israelita Brasileiro; colégios - Externato Misto Dr. Weizmann, Colégio Maghen David, depois Hebreu Brasileiro, e a Escola Scholem Aleichem; bibliotecas - BIBSA, H. N. Bialik e I. L. Peretz; grupos ideológicos e partidos movimento sionista Tifereth Tzion e os partidos sionista socialista Poalei

\footnotetext{
Uma das mais importantes é o minián, um grupo de dez homens para a reza. A existência do minián dispensa a existência de uma sinagoga, o que permite a reprodução dos laços (não apenas religiosos) mesmo na clandestinidade.
} 
Zion e o comunista Centro Operário Morris Vintschevsky; e outras entidades - a primeira organização comunitária, a União Israelita Shel Guemilut Hassadim é de 1830, e em 1910 foi fundado o Centro Israelita do Rio de Janeiro que, em 1924, transformou-se na agência local da Jewish Colonization Association." Em 1924 o rabino Isaias Rafalovitch, representante da $J C A$ veio ao Brasil para criar escolas, cooperativas de crédito e ajudar as instituições existentes.

Já na segunda década do século XX surgiram as entidades beneficentes com finalidades econômicas: a Achiezer ("ajuda ao irmão") e a Relief (Sociedade Beneficente Israelita de Amparo aos Imigrantes). A Relief era responsável pela recepção dos judeus refugiados recémchegados, pela ajuda financeira, pela obtenção de documentos e de postos de trabalho, pela guarda de bagagens, pelo ensino do português e pelo fornecimento das primeiras informações necessárias para "recomeçar a vida". Em 1923 foi inaugurada uma grande hospedaria para imigrantes judeus que recebiam, por uma semana, alojamento e refeições gratuitas. No final dos anos trinta a Relieftambém se responsabilizou pela assistência médica com a inauguração da Policlínica Israelita. Uma parte dos seus recursos provinham da $J C A$ e de instituições judaicas americanas (Hias e Joint) e européia (Emigdirect). A Froien Farein (Sociedade Beneficente das Damas Israelitas) foi criada para resolver assuntos familiares e sociais; entretanto, àquela época, uma de suas tarefas primordiais foi a de impedir que moças israelitas se tornassem vítimas da máfia da escravatura branca. Havia também o restaurante popular Arbeter Kich (Cozinha do Trabalhador). Em 1916 foi fundado o Comitê Brasileiro de Socorro às Vítimas da

A $J C A$ foi fundada pelo barão Maurice de Hirsch de Gereuth e sua primeira experiência de colonização (Moisesville) se deu em 1893 na Argentina. Entre 1904 e 1924, foram fundados assentamentosjudaicos no Rio Grande do Sul (Porto Novo) e em Santa Catarina (Hermat). Posteriormente criaram-se os do Paraná (Terra Norte) e do Rio de Janeiro (Resende). A compra de terras no Paraná contou com o apoio do Banco Warburg, sediado em Hamburgo, que colocava os interessados em contato com a empresa inglesa Paraná Plantations Ltd e a Cia. de Terras Norte do Paraná. Os ingleses da Paraná Plantations Ltd. permutavam o material ferroviário adquirido na indústria alemã (para a ligação de São Paulo ao norte do Paraná) por terras aos interessados em emigrar. A colônia de Resende foi, em 1936, uma tentativa de salvarjudeus alemães com a compra de parte da Fazenda da Barra. No início da construção da Escola Militar das Agulhas Negras em 1939, terrenos da "Fazenda dos Judeus" foram desapropriados e em alguns lotes cortados pela estrada Rio-São Paulo. A JCA acabou por se desfazer das terras disponíveis. 
Guerra e posteriormente o Centro Hebreu Brasileiro pró-vítimas da guerra.

Cabe acrescentar a União dos Prestamistas, uma cooperativa surgida para defender os interesses dos vendedores ambulantes, com a obtenção de mercadorias e serviços a preços baixos, contando inclusive com serviçojurídico para assistência fiscal e administrativa e o auxílio de despachantes, mas cuja vida foi breve. A Guemiluth Chessed Farain (Sociedade de Empréstimos de Favor) foi fundada por imigrantes ortodoxos com a finalidade de tornar-se uma caixa de empréstimos sem juros. Seus recursos eram constituídos por donativos e contribuições de sócios segundo a tradição das comunidades da Europa Oriental. No final dos anos vinte organizou-se o Banco Israelita Brasileiro cuja finalidade era desenvolver o comércio e a indústria da comunidade e que transformou-se posteriormente em sociedade anônima."

Devemos nos deter na Lai Spar Casse (Caixa de Empréstimos e Poupança, depois Sociedade Cooperativa de Crédito de Responsabilidade Limitada), fundada em 1927 com auxílio da JCA e da Relief. Constituía-se em uma cooperativa sem fins lucrativos com empréstimos a juros módicos com o objetivo de auxiliar os imigrantes que necessitavam recomeçar sua vida. Todo imigrante que tomava dinheiro emprestado tornava-se sócio e os membros mais ricos da comunidade faziam doações. O pagamento de uma pequena taxa e a aquisição de cotas "permitiam a qualquer pessoa da comunidade levantar imediatamente recursos que lhe estão vedados em outras instituições de crédito" (Lai Spar Casse, 1984). O pagamento era em cinco vezes e consta que nunca tenha havido inadimplência. ${ }^{6}$ Desta forma, além dos laços pessoais a colônia constituiu organizações capazes de socializarem os custos de integração do imigrante, eventualmente acima das possibilidades de seus familiares.

As atividades não-econômicas da comunidade permitiam, além da reprodução da vida social em um meio pouco acolhedor, a seleção de parceiros para atividades econômicas. Tal seleção não se limitava

O Banco Israelita Brasileiro, ao ser vendido em 1964, foi incorporado ao Banco Nacional de Minas Gerais.

Nos anos oitenta, com os juros atingindo altas taxas, seu capital foi minguando e a Diretoria solicitou aos sócios que cedessem suas cotas para poder realizar a liquidação extra-judicial. 
aos serviços profissionais (comércio e crédito, inclusive o trabalho assalariado). À medida que seus membros prosperavam e abriam ou ampliavam suas empresas, havia uma preferência pela contratação de membros da comunidade. Especialmente os contadores, advogados e vendedores eram escolhidos pela sua familiaridade com as práticas contábeis e mercantis correntes nas comunidades judaicas internacionais - outra vantagem comparativa em relação aos brasileiros. Este foi um importante impulso para que as novas gerações fossem encaminhadas para as universidades.

Mas, a própria educação dos filhos acabou por constituir-se em um elemento desagregador. Na medida em que jamais se fundou uma universidade judaica, os jovens que se dirigiam ao ensino superior adquiriam não apenas conhecimentos mas uma rede de relações que ampliava suas possibilidades de integração econômica e social sem depender da colônia. Livres da barreira lingüística em meados do século XX, estes israelitas penetraram no mercado de trabalho e contraíam casamentos exogâmicos, freqüentemente sem conversão (Sorj, 1997b). Eles mesmos e seus filhos foram adquirindo uma identidade de classe média ou de elite brasileiras que diluíram as fronteiras, agora desnecessárias, da colônia (Grin, 1997; Grun, 1997; Bernardo Sorj, 1997).

\section{Barreiras à entrada do imigrante no mercado brasileiro}

A principal barreira à integração do imigrante no mercado urbano é a falta de informações acerca das instituições vigentes. Destas, a mais importante e de mais difícil aprendizado é a língua. O maior problema para o recém-chegado, portanto, é de sustentar-se até que tenha ultrapassado tal obstáculo, e seja capaz de elaborar alguma estratégia de integração no mercado.

A segunda dificuldade à integração é o fato das relações econômicas no Brasil serem, muitas vezes, dependentes de vínculos de confiança pessoal. Esta é uma forma típica de reduzir custos de transação em economias em que os direitos de propriedade são frágeis, em função sobretudo do mal funcionamento do aparelho judiciário, incapaz de garantir o respeito aos contratos. Diante da fragilidade institucional, a garantia das transações não é a Lei, mas a honorabilidade das partes envolvidas. Sendo desconhecido, o imigrante terá dificuldade para realizar qualquer tipo de transação - seja vender algo, alugar uma moradia ou, sobretudo, realizar qualquer operação a crédito, por falta 
de fiador. Tais impasses são enfrentados mediante o recurso a dois tipos de organismos: as representações diplomáticas dos países com os quais o Brasil tem laços estreitos e as sociedades de ajuda mútua de sua colônia.

Os problemas de adaptação irão variar segundo a dotação individual de fatores de produção e seu grau de inserção na comunidade. Um indivíduo que tenha trazido riqueza líquida pode aplicá-la e transformar-se em empresário desde que consiga formar uma sociedade com aqueles que já conhecem o mercado. Uma das formas mais simples ocorre com a usura, sistema de crédito informal amplamente praticado quando o sistema financeiro nacional era atrofiado. O imigrante poderia, portanto, confiar seu dinheiro mediante uma comissão, enquanto não fosse capaz de estabelecer-se por conta própria e na aquisição de uma participação societária em uma firma. Aqueles que, além de possuírem riqueza sob forma líquida, tinham alguma capacidade de se fazer entender, ${ }^{8}$ podiam entrar no comércio atacadista ou varejista, como mostram os diversos exemplos relatados por Fausto (1997).

No caso de profissionais liberais, a integração se deu de forma diferenciada antes e depois dos anos vinte. Nestes períodos estava em jogo sua capacidade de comunicação com a clientela - a barreira lingüística e seu "bom nome". Por isso, sua atuação ficava freqüentemente ligada ao espaço da colônia e seu sistema informal de ajuda mútua. Por exemplo, um médico polonês ficava restrito aos clientes que falavam sua língua, ou o íidiche. A partir dos anos trinta, com a regulamentação corporativa das profissões liberais, acrescentou-se uma outra barreira à entrada no mercado: a aceitação da validade de seu diploma, por vezes perdido na viagem ou oriundo de alguma faculdade não reconhecida pelas autoridades corporativas brasileiras. Por isso o imigrante profissional liberal poderia permanecer em uma

Trata-se, de uma maneira geral, daqueles que conseguiram programar sua emigração e vender seus bens a preços relativamente satisfatórios. Os emigrantes de última hora, que esperavam que a perseguição se revelasse insuportável para deixar seu país, freqüentemente se desfaziam de seus patrimônios na "bacia das almas", trazendo pouco mais do que a roupa do corpo ou algumajóia de família.

Por exemplo, os judeus sepharadim (oriundos do Marrocos, Ilha de Rodes, Síria, Líbano, Egito, Grécia e Turquia) falam ladino, língua que uma vez mesclada com algumas palavras de português pode ser compreendida por qualquer brasileiro. 
situação de clandestinidade, não por realizar uma atividade proibida, mas por falta do reconhecimento de sua habilitação.’

Já para os artesãos especializados - como barbeiros, alfaiates ou ourives - o vocabulário específico não constituía uma barreira difícil de superar, podendo partir de uma atuação restrita à clientela da colônia e chegar a atingir o grande público. Neste caso parece que o maior obstáculo estaria em conseguir um ponto comercial, o que poderia ser feito diretamente (alugando-se o imóvel a um patrício) ou indiretamente (com um aval fornecido pela colônia). Assim, estes imigrantes tendiam a concentrar-se nos bairros onde moravam seus iguais, tanto para superar obstáculos do lado da oferta (o ponto comercial) quanto do lado da demanda (a clientela), segundo uma variante étnica do distrito industrial marshalliano. Entre os anos 1910 e 1940, muitos judeus viviam nos arredores da Praça Onze, na área central do Rio de Janeiro, e que era o centro da comunidade. Ali se localizavam suas casas comerciais, oficinas e instituições religiosas, filantrópicas, culturais, sociais, recreativas e ideológicas. Os proprietários de lojas e de pequenas manufaturas em geral residiam no segundo andar dos sobrados, enquanto que os trabalhadores muito pobres moravam em cortiços. O bairro suburbano de Madureira e o vilarejo de Nilópolis, este último localizado na atual Baixada Fluminense, também possuíam numerosos moradores de origem israelita. Estes judeus estavam acima da linha da miséria típica dos moradores dos cortiços, mas, ou eram pobres bastante para não poderem morar em locais com melhores condições urbanas, ou por não quererem abandonar a convivência com a vizinhança.

Outro tipo de profissional qualificado eram os especialistas em comércio, que ao mesmo tempo contornavam a barreira lingüística e ainda dominavam a arte da barganha. Estes podiam empregar-se como compradores/vendedores das firmas da colonia. Ainda entre os profissionalmente qualificados citamos os gráficos e linotipistas que formaram suas pequenas empresas ou trabalhavam para os periódicos judaicos escritos em ídiche. Aliás, esta parece ter sido uma atividade no Rio de Janeiro em que a participação de imigrantes de várias nacionalidades foi predominante.

\footnotetext{
No Rio de Janeiro um conhecido médico judeu, o Doutor Munck, clinicava clandestinamente no interior da colônia. Muito respeitado, era inúmeras vezes convocado como árbitro de querelas comerciais e familiares.
} 
No caso de imigrantes destituídos de capital ou de qualquer habilitação profissional especial, uma opção era a agricultura, para o que eram oferecidas diversas facilidades pela Jewish Colonization Association. Aqueles que preferissem fixar-se no meio urbano tinham que enfrentar as restrições anteriormente citadas. Observe-se que um importante elemento de formação da renda familiar era o trabalho feminino, como o de costureira ou doceira. Estas atividades, porém, eram mal remuneradas, servindo apenas de complemento ao sustento da família.

A partir dos anos trinta foram sendo promulgadas leis restritivas à imigração, fechando-se as fronteiras aos que não eram cristãos, europeus e agricultores. Este obstáculo foi parcialmente superado a partir de 1934 mediante o instrumento da carta de chamada, cujos formulários tinham de ser aprovados pela polícia, enviadas pelos imigrantes já estabelecidos, ou com a apresentação de títulos de compra de terras, (ver nota 4) O Brasil não passava por um processo de industrialização acelerado como o existente nos EUA, onde havia uma demanda elevada por mão-de-obra com diversos graus de qualificação. Mesmo nos EUA, porém, o acesso ao emprego geralmente passava pela filiação a sindicatos controlados pelas colônias e ligados a partidos políticos. ${ }^{10} \mathrm{Na}$ ausência de tais oportunidades no Brasil, o imigrante ficava restrito aos serviços urbanos. Além da óbvia possibilidade de tornar-se um assalariado (condutor de bondes, linotipistas e gráficos, operários, alfaiates, costureiras, sapateiros, carpinteiros, açougueiros, pedreiros, barbeiros, fotógrafos, peleteiros, marinheiros, ourives, ferreiros, dentistas, funileiros, guarda-livros, atores, rabinos, fabricantes de salames, soichets, músicos e tapeceiros), poderia tornarse um mascate, caso que examinaremos a seguir.

\section{A atrofia da rede comercial formal e o espaço para o mascate}

Depois das leis restritivas à imigração dos EUA, do Canadá e da Argentina, entraram no Brasil entre 1920 e 1930 aproximadamente 30 mil judeus (Avni, 1992), e no período de 1933 a 1942 chegaram legalmente outros 25 mil, muitos dos quais pertencentes às classes menos favorecidas e vindos da Alemanha e da Polônia. Um percentual

\footnotetext{
${ }^{10}$ Sobre a assimilação do imigrante nos EUA e o papel das colônias ver Muhlstein (1991), capítulos 6 e 7.
} 
muito reduzido entre os imigrantes possuía profissão e a maioria pertencia às classes baixa e média-baixa. Para Lesser (1995) $35 \%$ dos que chegavam não possuíam qualquer profissão e tornavam-se klienteltshik, atividade também praticada na Argentina, onde era conhecida por cuasitenik ("vendedor a cuenta") e no Chile, por "semanalero".

Esta atividade era tradicional, no Brasil como em todo o mundo. A etimologia de mascate mostra que a palava vem da cidade de Mascat, na Arábia Saudita, onde navegantes portugueses aportavam para comerciar. Goulart (1967) refere-se a judeus mascates clandestinos operando no litoral brasileiro desde Curitiba até Natal no século XIX. O geógrafo Pierre Deffontaines (1947) apontou a origem dos mascates nos tropeiros portugueses da Colônia que iam do sertão ao litoral em busca de mercadorias encomendadas pelos senhores de engenho. Com o café, o campo de atividades dos então vendedores ambulantes italianos passou a concorrer com os armazéns das fazendas. Teria havido uma terceira onda por volta de 1885-90 com os sírios (maronitas), que ficaram conhecidos por todo o interior do país. Eram vendedores que em muitas ocasiões tornavam-se também compradores de produtos locais (gado, arroz, aguardente, metais preciosos e borracha).

Um caso exemplar foi o da imigração de judeus oriundos da França, do Oriente Próximo e do norte da África para a Amazônia durante o boom da borracha. Uns poucos conseguiram levantar o montante de capital necessário para a prática do comércio internacional aproveitando sua rede de conhecimentos no exterior. A grande maioria, porém, ficou restrita ao pequeno comércio, explorando as dificuldades oriundas da precariedade da rede local de transportes. Eram os regatões que atuavam em duas pontas: na primeira, às margens dos distantes igarapés, vendiam bens de consumo aos seringueiros e compravam sua produção de borracha ou de castanhas e demais frutos do extrativismo. Na outra ponta, em Belém e Manaus, vendiam sua carga e adquiriam o estoque para sua próxima viagem (Blay, 1997).

Os judeus eram apenas um dos grupos de mascates amazônicos. Sua vantagem comparativa estava na sua maior capacidade de alavancar crédito para as operações de compra do estoque inicial, mediante o comprometimento da venda da viagem. Por outro lado, este crédito era repassado aos extrativistas com o empenho da produção futura. Não encontramos informações sobre os mecanismos de financiamento, garantias e taxas de juros. Importa destacar que foram estas 
práticas que deram origem a redes de crédito comercial distribuídas para o resto do País através da migração que se seguiu à decadência da borracha amazônica.

Maiores informações foram obtidas para o caso dos mascates urbanos. O comércio dos bairros afastados dos centros das cidades estava reduzido, naquela época, a uns poucos armazéns de comestíveis, padarias, botequins e lojas de artesãos, como barbeiros e eletricistas. Os ambulantes judeus vendiam a prestação - sobretudo tecidos, produtos de armarinho, artigos de cama, mesa e banho, roupas prontas inclusive ternos, artigos de cama, mesa e banho, móveis e jóias. O klienteltshik, ao operar com prestações ao alcance das rendas que sobravam às donas de casa, aumentava as vendas e atingia os consumidores mais pobres.

Para entrar no ramo era necessário que alguém da colônia apresentasse o novato aos donos de lojas e de fábricas, que lhe assegurariam o pagamento das mercadorias entre 90 e 120 dias. Para Malamud "neste ínterim, o vendedor ambulante, quando era trabalhador, capaz e esforçado, criava para si uma base econômica. A maioria dos prestamistas vivia no primeiro período de sua atividade fazendo uma economia severa em todos os sentidos, para poder adquirir uma situação mais estável, ou seja, um equilíbrio financeiro." (1988:28)

A colônia proporcionava dois elementos fundamentais para a entrada do imigrante no comércio ambulante: o menino e o pacote. $\mathrm{O}$ menino era um imigrante capaz de orientar-se pela cidade e de falar tanto a língua de seus pais quanto o português. Sua função era intermediar os negócios, ensinar-lhe os nomes das ruas e servir de intérprete. O pacote era um conjunto de mercadorias obtidas a crédito junto aos atacadistas da colônia, que lhe permitia constituir sua canastra e começar a operar. Com o correr do tempo o menino se tornava dispensável (tendo, em troca, ganho algum dinheiro mas sobretudo aprendido a arte da barganha), mas o crédito obtido para a reposição do pacote continuava sendo a chave para a sobrevivência da atividade. Além disso, o prestamista, ao prosperar, contratava um carregador.

A principal explicação para a ausência do comércio formal nos bairros, principalmente dos subúrbios da zona norte da cidade do Rio de Janeiro, parece ter estado no baixo poder aquisitivo da população, que gerava três restrições: (a) não se atingia a escala mínima'

\footnotetext{
'Para Chandler (1990), os ganhos de escala aparecem quando o aumento na quantidade distribuída de um produto gera um custo médio menor, pelo uso mais intensivo de
} 
que permitisse a instalação de distribuidoras monoproduto, como roupas feitas; (b) havia economias de escopo em distribuidoras multiproduto de secos e molhados, mas não de outros bens de consumo em função do custo de instalação; ${ }^{12}$ e (c) a necessidade de oferecer crédito ao consumidor incapaz de realizar operações à vista (seja em função da periodicidade variável do fluxo de renda de trabalhadores autônomos, seja em função do alto preço unitário do bem face à renda disponível), e do elevado custo de transação embutido nas operações de crédito tanto diante da lei da usura como da pequena capacidade do aparelho judicial para garantir o cumprimento dos contratos.

A vantagem comparativa do mascate derivava de um trade-offentre seu esforço físico e sua capacidade de reduzir custos de instalação, de estocagem e de transação. Os custos de instalação e estocagem eram quase nulos na medida em que o negócio não incluía uma loja, com seus custos de aquisição (ou aluguel) e impostos. O klienteltshik os substituía carregando seu reduzido estoque em uma canastra (baú, mala de mão ou carroça). Ao trabalhar com encomendas, podia repassar o custo da estocagem ao atacadista, o que se constituía num antepassado do just in time. Em troca, o profissional incorria no ônus de carregar na canastra um mostruário variado, de forma a apropriarse de economias de escopo diante da demanda de uma clientela de baixa renda por tais produtos.

A capacidade de reduzir custos de transação permitia a mascate conceder crédito. Ainda que os armazéns vendessem informalmente pelo sistema do caderno, tratava-se de operações de curto prazo, geralmente de uma a quatro semanas. As vendas a prestação por prazos mais dilatados, em geral 15 meses, esbarrava na dificuldade de finan-

um insumo qualquer. Os ganhos de escopo surgem quando o mesmo resultado ocorre pela distribuição de um novo produto em paralelo ao primeiro, igualmente pelo uso mais intensivo de um insumo. Custos de transação são aqueles envolvidos nas transferências de bens e serviços (compra e venda de mercadorias), referentes a problemas derivados do não-pagamento de dívidas ou da diferença de opiniões do comprador e do vendedor em relação à qualidade e à quantidade dos produtos.

Um armazém de secos e molhados opera em condições incompatíveis com a distribuição de roupas, sobretudo em um momento em que a indústria de plásticos ainda não desenvolvera o filme de polietileno, capaz de defender o tecido contra a poeira. O desgaste de um estoque de tecidos em um armazém expressaria uma deseconomia de escopo capaz de afastar o empresário deste tipo de atividade. O mesmo pode ser aplicado aos demais produtos comercializados pelo mascate. 
ciar seus próprios estoques - sobretudo porque a lei da usura limitava em $12 \%$ a taxa anual de juros - e na fragilidade dos direitos de propriedade, que daria poucas garantias de sucesso caso se levasse o inadimplente aos tribunais - o que reduzia a possibilidade do armazém obter crédito dos fornecedores.

O vendedor ambulante, por sua vez, tinha maiores informações sobre o cliente, na medida em que conhecia sua moradia e, através de contatos com a vizinhança, podia ter uma avaliação mais precisa sobre a solvabilidade de cada devedor. Assim a venda a prestação para o consumidor se efetivava através do sistema de cartões de controle da dívida, sempre em duas vias, uma que ficava com o prestamista e a outra com o cliente. Era este o sistema de controle mútuo denominado klienteltshik. Não existem evidências acerca das taxas de juros praticadas em tais operações. Segundo entrevistas, uma boa aproximação seria o mascate adquirir o produto com $30 \%$ de desconto sobre o preço no varejo e repassá-lo com juros simples de $3 \%$ ao mês. Os maus pagadores eram conhecidos por tzvekes (pregos), informação logo repassada aos demais ambulantes. A possibilidade de ostracismo servia para reduzir os custos de transação nas operações de crédito informal.

O sistema não tinha valor legal para a defesa do credor, mas este era obrigado a correr o risco caso quisesse subsistir numa sociedade que oferecia poucas oportunidades de trabalho. Ao mesmo tempo, era a única forma pela qual a população de baixa renda podia ter acesso àqueles bens, tendo interesse portanto em honrar o compromisso informal. À medida que aumentava a confiança entre as partes, podiam chegar a ser financiados bens de valor elevado, como os eletrodomésticos e móveis mais sofisticados. Desta forma, passavase de uma atividade comercial e de crédito baseada na exibição da amostra para uma atividade essencialmente financeira.

Não se tratava de atividade que conferisse riqueza nem status elevado. Os prestamistas freqüentemente eram pouco menos pobres do que seus clientes, morando nos mesmos bairros e sofrendo discriminação - no Rio de Janeiro eram chamados de "judeus da prestação" e, em São Paulo, de "russos da prestação". A clientela não podia ser expandida para além dos limites da população de baixa renda em função do forte preconceito das camadas de rendas média e alta contra as operações a crédito. Comprar "a prestação" denotava pobreza ou ainda pior, prodigalidade, a incapacidade de viver dentro do limite de seus meios. 
Foi apenas nos anos sessenta que desapareceu tal opinião, com a extinção da lei da usura e o forte estímulo ao crédito direto ao consumidor através das chamadas financeiras (Sociedades de Crédito, Financiamento e Investimentos) alavancando as transações com bens de consumo duráveis, e com o Sistema Financeiro da Habitação fazendo o mesmo com o crédito habitacional. Foi preciso que a classe média urbana fosse obrigada a aderir às prestações para ter acesso aos novos bens de consumo para que o preconceito fosse substituído pela aceitação eufórica do endividamento.

\section{Conclusão}

A existência de mascates é uma característica de sociedades em que o comércio formal e o sistema financeiro não ocuparam ainda todos os espaços existentes para transações mercantis. Em um ambiente econômico assim restrito aparecem nichos para atividades informais, intensivas em trabalho, desde que o mascate consiga os insumos necessários a seu negócio - a mercadoria e o crédito. Os laços de solidariedade da colônia propiciaram aos imigrantes judeus, durante décadas, esta vantagem competitiva que permitiu a inserção de tantos recém-chegados na economia fluminense. Hoje os klienteltshik desapareceram, mas não o comércio informal: foram substituídos pelas sacoleiras sem origem étnica precisa, que vendem em sua vizinhança e concorrem com o crédito dos grandes magazines; e pelos camelôs, espalhados por todas as cidades. Ambos merecem ser estudados.

\section{Referências bibliográficas}

Avni, Haim. Judíos en América. Madrid: Editorial Mapfre, 1992.

Backheuser, Everardo. Comércio ambulante e ocupações de rua no Rio de Janeiro. Revista Brasileira de Geografia (1), janeiro-março de 1944.

Ben-Porath, Yoram. The F-Connection: Families, Friends and Firms and the Organization of Exchange. Population and Development Review (1), vol. 6, 1980.

Blay, Eva A. Judeus na Amazônia, in Bila Sorj (1997).

Carneiro, Maria Luiza Tucci. Brasil, um Refúgio nos Trópicos. A trajetória dos refugiados do nazi-fascismo. São Paulo: Estação Liberdade, 1996.

Castells, Manuel. The Power of Identity (The Information Age, vol. 2). Pasdtow, Malden e Oxford: Blackwell Publishers, 1997. 
ChandlerJr. ,Alfred D. Scale and Scope. The dynamics of industrial capitalism. Cambridge (Mass.) and London: Harvard University Press, 1990. Deffontaines, Pierre. Os mascates ou mercadores ambulantes do Brasil. Boletim Geográfico (55), 1947.

Fausto, Boris. Negócios e Ócios. São Paulo: Companhia das Letras, 1997. Imigração: cortes e continuidades. In L. M. Schwarcz (org.), História da Vida Privada no Brasil, volume 4. São Paulo: Companhia das Letras, 1998. [org.].

Fazer a América: a imigração em massa para a América Latina. São Paulo: Edusp, 1999.

L'immigration juive au Brésil (1920-1940). In Bart de Prins, Eddy Stols e Johan Verberckmoes (eds.) Brasil. Cultures et Economies de quatre continents. Leuven: Acco, 2001.

Goldman, Xie. Era uma vez, em Nilópolis. ASA Judaísmo e Progressismo (58), 1999.

Goulart, José Alipio. O Mascate no Brasil. Rio de Janeiro: Editora Conquista, 1967.

Grin, Mônica. Diáspora minimalista: a crise do judaísmo contemporâneo, in Bila Sorj (1997).

Grun, Roberto. Intelectuais na comunidade judaica brasileira, in Bila Sorj (1997).

Construindo um lugar ao sol: os judeus no Brasil, in Fausto (1999).

Lai Spar Casse Um Banco Filantrópico. A Lai Spar Casse do Rio de Janeiro. Rio de Janeiro:s.n., 1984.

Lesser, Jeffrey. O Brasil e a Questão Judaica. Imigração, diplomacia $e$ preconceito. Rio de Janeiro: Imago, 1995.

London, Esther. Vivência Judaica em Nilópolis. Rio de Janeiro: Imago, 1999.

Lozinsky, Saádio. Memórias da Imigração. Reminiscências e reflexões. Rio de Janeiro: Garamond, 1997.

Malamud, Samuel. Recordando a Praça Onze. Rio de Janeiro: Livraria Kosmos Editora, 1988.

Muhlstein, Anka. A Ilha Prometida. A história de Nova York do século XVII aos nossos dias. São Paulo: Companhia das Letras, 1991.

Neiva, Artur Hehl. Estudos sobre a imigração semita no Brasil. Revista de Imigração e Colonização (2), junho de 1944.

Niskier, Moszek. De Ostrowiec ao Rio de Janeiro. Rio de Janeiro: s.n., 1991.

Schneider, Abraham Josef. História da BIBSA. Crônicas de um judeu progressista. Rio de Janeiro:ASA, 2000. 
Solomon, Marcelo. Aspectos Sócio-Econômicos da Imigração Judaica para o Brasil. Rio de Janeiro: IE/UFRJ, Monografia de Bacharelado, mimeo., 1999.

Sorj, Bernardo. Sociabilidade brasileira e identidade judaica, in Bila Sorj (1997).

Sorj, Bila [org.]. Identidades Judaicas no Brasil Contemporâneo. Rio de Janeiro: Imago, 1997

Normalizando o povo judeu: a experiência da Jewish Colonization Association no Brasil, in Bila Sorj (1997).

Thompson, Paul. A Voz do Passado. História oral. São Paulo: Paz e Terra, 1998 ( $2^{\circ}$ ed).

Veltman, Henrique. A História dos Judeus no Rio de Janeiro. Rio de Janeiro: Editora Expressão e Cultura, 1998.

Wolff, Egon e Wolff, Frieda. Judeus nos Primórdios do Brasil República. Rio de Janeiro: Centro de Documentação da Biblioteca Israelita H.N. Bialik, 1979.

Depoimentos. Um perfil da coletividade judaica brasileira. R i o de Janeiro: IHGB, 1988.

Coletânea de Artigos e Conferências. Nachman Falbel (org.). Rio de Janeiro: IHGB, 1991.

Fatos Históricos e Mitos da História dos Judeus no Brasil. Rio de Janeiro: Xenon Editora, 1996.

Worcman, Susane; Feller,Aicila; Worcman, Karen. Heranças e Lembranças. Imigrantes judeus no Rio de Janeiro. Rio de Janeiro: A RI:CIEC:MIS, 1991. 